\title{
Phenazine carboxylic acid and its derivative induce osteoblast differentiation in preosteoblastic MC3T3-E1 cells but adipocyte differentiation in pluripotent mesenchymal C3H10T1/2 cells
}

\author{
Shuichi Sakamoto ${ }^{1}$, Takumi Watanabe ${ }^{2}$, Yasuko Kohda ${ }^{1}$, Masatomi Iijima ${ }^{1}$, Ryuichi Sawa ${ }^{2}$, Maiko Okada ${ }^{3,4}$, \\ Hayamitsu Adachi ${ }^{1}$, Yoshio Nishimura ${ }^{2}$ and Manabu Kawada ${ }^{1,2}$ \\ Osteoblast and adipocyte are differentiated from mesenchymal stem cells and dysregulation of the differentiation might result in disease, \\ such as osteoporosis and diabetes. To find small compounds that induce osteoblast differentiation, we screened an in-house natural \\ compounds library with mouse preosteoblastic MC3T3-E1 cells using alkaline phosphatase (ALP) expression as an early osteoblast \\ marker. We found that phenazine-1-carboxylic acid (PCA), one of the major phenazine derivatives produced by Pseudomonas, induced \\ osteoblast differentiation in the cells at micromolar concentrations. PCA acted synergistically with an agonist of hedgehog signaling in \\ inducing ALP activity in the cells. We also found that 2-hydroxy-PCA (2H-PCA) induced osteoblast differentiation in the cells but 2- \\ methoxy-PCA and 1-hydroxy-phenazine did not. Unexpectedly, treatment of mouse pluripotent mesenchymal C3H10T1/2 cells with PCA \\ or 2H-PCA induced an obvious morphological change. Oil Red 0 staining and real-time reverse-transcription PCR analysis revealed that \\ PCA induced not osteoblast differentiation but adipocyte differentiation in C3H10T1/2 cells. These compounds could allow us to \\ investigate the mechanism of osteoblast and adipocyte differentiation in the two model cell systems through a chemical biology \\ approach.
}

The Journal of Antibiotics (2017) 70, 1146-1149; doi:10.1038/ja.2017.129; published online 25 October 2017

Mesenchymal stem cells (MSCs) are adult stem cells that carry potential for differentiation into various cell lineages, such as osteoblasts and adipocytes. ${ }^{1}$ These cell lineages are important for bone and lipid homeostasis in the body. ${ }^{2,3}$ MSC differentiation is tightly controlled by the local environment in the body and an imbalance of MSC differentiation might result in disease, such as osteoporosis and diabetes. In addition, MSCs can be easily isolated from bone marrow and adipose and are one of the major cell sources for regenerative therapy. ${ }^{1}$ Therefore, small compounds that affect MSC differentiation such as osteogenesis and adipogenesis could be useful for study of these events and might provide important knowledge for the development of regenerative therapy and novel drugs.

To find small compounds that induce osteoblast differentiation, we screened an in-house natural compounds library with mouse preosteoblastic MC3T3-E1 cells using alkaline phosphatase (ALP) expression as an early osteoblast marker. ${ }^{2}$ In the course of the screening, we found that phenazine-1-carboxylic acid (PCA), one of the major phenazine derivatives produced by Pseudomonas, ${ }^{4}$ induced ALP activity in MC3T3-E1 cells at micromolar concentrations (Figure 1b). The induction of ALP activity by PCA was dose- dependent and was weaker than that of purmorphamine, a smallmolecule agonist of hedgehog signaling ${ }^{5}$ (Figure 1c). Real-time reverse-transcription PCR analysis revealed that 7-day treatment with $10 \mu \mathrm{M}$ PCA induced Alpl mRNA, the gene encoding ALP. PCA also induced the mRNA expression of the osteoblastic genes Ocn, Opn and Runx2 (Figure 1d). Interestingly, we found that PCA acted synergistically with purmorphamine in inducing ALP activity in MC3T3-E1 cells (Figure 1e). These data demonstrated that PCA induces osteoblast differentiation in MC3T3-E1 cells.

We next examined whether the three phenazine derivatives, 2hydroxy-PCA (2H-PCA), 2-methoxy-PCA (2ME-PCA) and 1hydroxy-phenazine (1H-phenazine), could induce osteoblast differentiation in MC3T3-E1 cells. A 7-day treatment with $10 \mu \mathrm{M} 2 \mathrm{H}$-PCA also induced mRNA expression of the osteoblastic genes Alpl, Ocnand Runx2 (Figure 1d). However, treatment with 2ME-PCA or $1 \mathrm{H}-$ phenazine had no effect on these genes (Figure 1d). At this concentration, these compounds did not show any cytotoxic effects on the cells at the cellular density of the differentiation experiments (Supplementary Figure S1). We also performed a time course (4, 8 and 12 days) study about the effect of $2 \mathrm{H}$-PCA treatment on the osteoblast

${ }^{1}$ Microbial Chemistry Research Foundation, Institute of Microbial Chemistry, Numazu Branch, Shizuoka, Japan; ${ }^{2}$ nnstitute of Microbial Chemistry, Tokyo, Japan; ${ }^{3}$ St Marianna University School of Medicine, Kanagawa, Japan and ${ }^{4}$ School of Bioscience and Biotechnology, Tokyo University of Technology, Tokyo, Japan

Correspondence: Dr S Sakamoto, Microbial Chemistry Research Foundation, Institute of Microbial Chemistry, Numazu Branch, 18-24 Miyamoto, Numazu, Shizuoka 410-0301, Japan.

E-mail: sakamotos@bikaken.or.jp

Received 17 October 2016; revised 12 September 2017; accepted 25 September 2017; published online 25 October 2017 
a

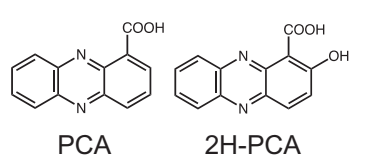<smiles>COc1c(CO)ccc2nc3ccccc3nc12</smiles>

1H-Phenazine 2ME-PCA b

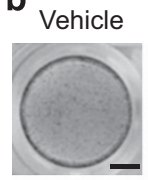

PM

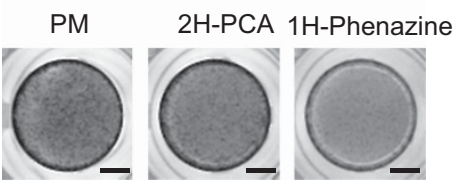

C

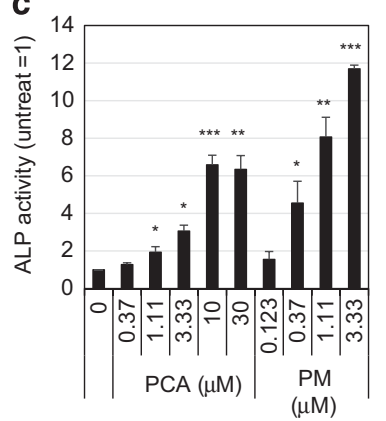

e

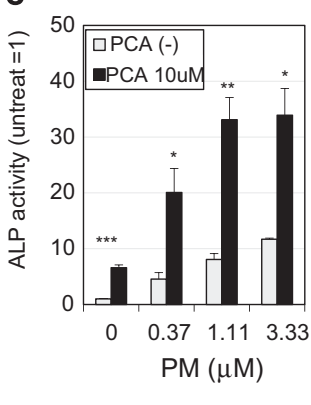

Figure 1 Phenzazine-1-carboxylic acid (PCA) treatment induces osteoblastic differentiation of the mouse preosteoblast cell line MC3T3-E1. (a) Chemical structures of phenazine derivatives used in this study. (b) MC3T3-E1 cells were treated with $10 \mu \mathrm{m}$ of indicated compounds in 96-well plates. After 6 days of treatment, cells were fixed and stained for ALP. Scale bars $=200 \mu \mathrm{m}$. (c) MC3T3-E1 cells were treated with PCA or purmorphamine (PM) at increasing concentrations as indicated. After 6 days of treatment, ALP activities were measured using AttoPhos substrate. Data are shown as the mean and s.d. of three independent experiments performed in duplicate. ${ }^{*} P<0.05,{ }^{*} P<0.01$ and ${ }^{* * *} P<0.005$, Student's $t$-test, compared with untreated controls. (d) Real-time reverse-transcription PCR (RT-PCR) analysis of osteogenic genes Alpl, Ocn, Osteopontin (Opn) and Runx2. Cells were treated with $10 \mu \mathrm{m}$ PCA derivatives for 7 days and then total RNA was extracted and subjected to real-time RT-PCR. Data were first normalized to the level of Gapdh and are presented as fold change versus vehicle controls. Data represent the mean and s.d. of three independent experiments. ${ }^{*} P<0.05,{ }^{* *} P<0.01$ and ${ }^{* * *} P<0.005$, Student's $t$-test, compared with vehicle controls. (e) ALP activities were measured after 6 days of combination treatment of $10 \mu \mathrm{m}$ PCA with PM. Data are shown as the mean and s.d. of three independent experiments performed in duplicate. ${ }^{*} P<0.05,{ }^{*} P<0.01$ and ${ }^{* * *} P<0.005$, Student's $t$-test, compared with PCA ( ) group. A full colour version of this figure is available at the Journal of Antibiotics journal online.

differentiation of MC3T3-E1 cells (Supplementary Figure S2). In 2HPCA treatment cells, expression of the early osteoblast maker Alpl reached a peak level at day 4 but expression of the late osteoblast marker Ocn increased during the 12-day treatment. Thus, our results demonstrated that the two phenazine derivatives have osteogenic activity on MC3T3-E1 cells and that the functional groups at C-1 and C-2 substantially affect the potency of the osteogenic activity of the phenazine derivatives.

Mouse pluripotent mesenchymal C3H10T1/2 cells, such as MSCs, are able to differentiate into various cells such as osteoblasts and adipocytes. ${ }^{6-8}$ Next, we investigated the effect of PCA on the differentiation of $\mathrm{C} 3 \mathrm{H} 10 \mathrm{~T} 1 / 2$ cells. After an 8-day treatment with $10 \mu \mathrm{M}$ PCA, C3H10T1/2 cells showed an obvious morphological change. This morphological change was same as that of $\mathrm{C} 3 \mathrm{H} 10 \mathrm{~T} 1 / 2$ cells treated with troglitazone, an activator of nuclear receptor peroxisome proliferator-activated receptor- $\gamma(\operatorname{PPAR} \gamma)$ that induces adipogenesis in the cell line. ${ }^{9}$ Oil Red $\mathrm{O}$ staining supported the conclusion that the morphologically changed cells were adipocytes (Figure 2a). The induction of Oil Red O-positive cells by PCA was dose dependent (Figure 2b). Real-time reverse-transcription PCR analysis demonstrated that 8-day treatment with $10 \mu \mathrm{M}$ PCA-induced expression of adipogenic genes Fabp4, Lpl, Adiponectin and Cebpa (Figure 2c). We also investigated whether the three phenazine derivatives could induce adipocyte differentiation in $\mathrm{C} 3 \mathrm{H} 10 \mathrm{~T} 1 / 2$ cells. The 8-day treatment with $10 \mu \mathrm{m} 2 \mathrm{H}-\mathrm{PCA}$ induced Oil Red O-positive cells in a dose-dependent manner
(Figure 2b). However, treatments with 2ME-PCA or 1H-phenazine did not induce Oil Red O-positive cells (Figure 2b). Treatment with $10 \mu \mathrm{M} 2 \mathrm{H}-\mathrm{PCA}$ also induced mRNAs of the adipogenic genes, but treatment with 2ME-PCA or $1 \mathrm{H}$-phenazine had no effect on these levels (Figure $2 c$ and Supplementary Figure S2). On the other hand, the early osteoblastic marker ALP activity was not induced by treatment with PCA and its derivatives in C3H10T1/2 cells (Supplementary Figure S4). These results demonstrated that PCA and $2 \mathrm{H}-\mathrm{PCA}$ induce adipocyte differentiation rather than osteoblast differentiation in C3H10T1/2 cells, and that the functional groups at $\mathrm{C}-1$ and $\mathrm{C}-2$ also substantially affect the potency of the adipogenic activity of phenazine derivatives. This parallel relationship between structures and activities in osteoblast differentiation in MC3T3-E1 cells and adipocyte differentiation in C3H10T1/2 cells could imply the existence of a common target(s) in both cell lines. We also examined whether $2 \mathrm{H}-\mathrm{PCA}$ could induce differentiation of mouse MSCs derived from the bone marrow of C57BL/6 mice (Supplementary Figures S5 and S6). However, the treatment with 2H-PCA did not induce osteogenic and adipogenic differentiation on the mouse MSCs in our experimental conditions.

As both Fabp4 and $L p l$ are transcriptional target genes of PPAR $\gamma$, we next investigated whether 2H-PCA could enhance PPAR $\gamma$-activated transcription using a PPAR $\gamma$ reporter assay in $\mathrm{C} 3 \mathrm{H} 10 \mathrm{~T} 1 / 2$ cells and MC3T3-E1 cells (Figure 2d). Treatment with $10 \mu \mathrm{M}$ troglitazone induced PPAR $\gamma$ reporter activation by approximately twofold compared with control in both cell lines. In contrast, treatment with $10 \mu \mathrm{M}$ 
a

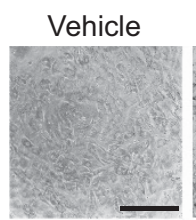

TRO

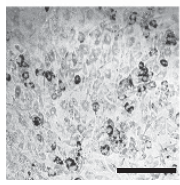

c

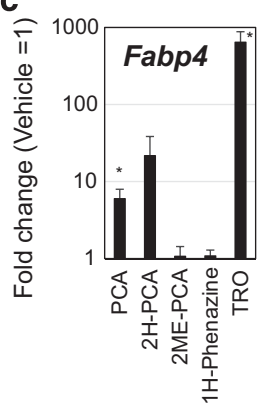

PCA

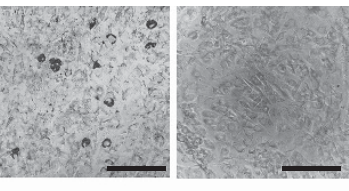

2H-PCA 1H-Phenazine
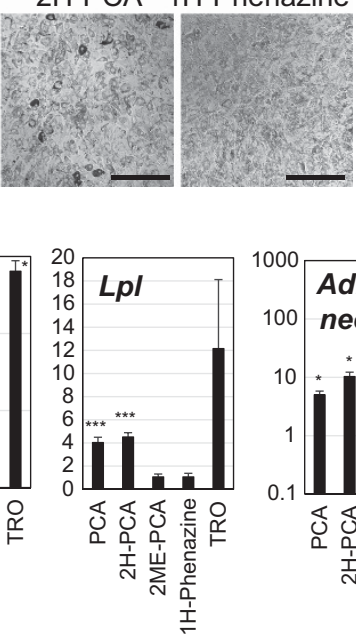

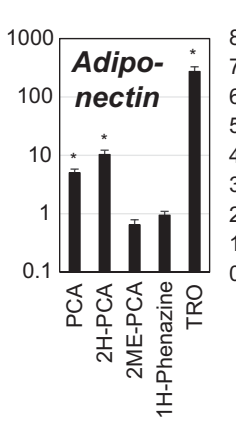

b

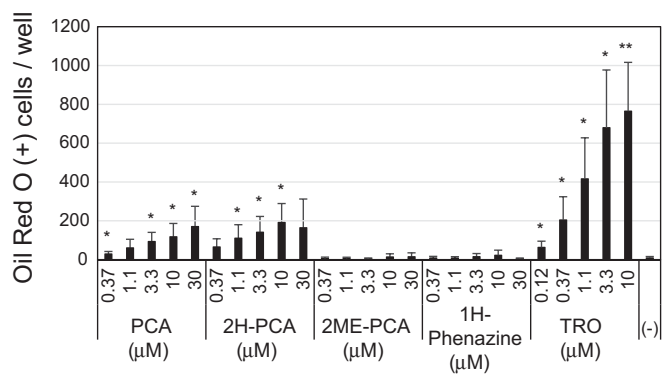

d
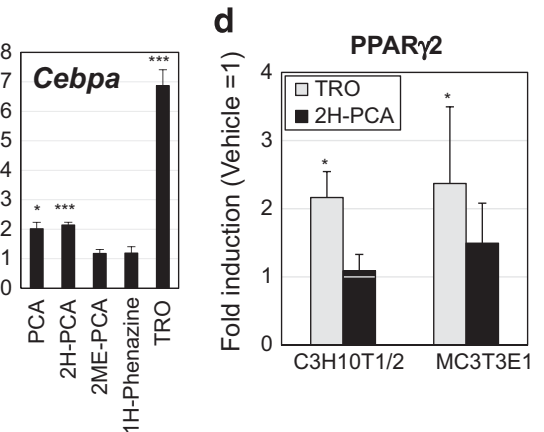

Figure 2 PCA treatment induces adipocyte differentiation in the mouse pluripotent mesenchymal cell line C3H1OT1/2. (a) C3H10T1/2 cells were treated with $10 \mu \mathrm{m}$ of the indicated compounds for 8 days in 96-well plates and stained with Oil Red 0 . The images were taken at $\times 100$ magnification. Scale bars $=200 \mu \mathrm{m}$. (b) Numbers of Oil Red $\mathrm{O}(+)$ cells in each well were quantified by light microscopy. Data are shown as the mean and s.d. of three independent experiments performed in duplicate. (c) Real-time reverse-transcription PCR (RT-PCR) analysis of adipogenic genes Fabp4, Lpl, Adiponectin and Cebpa. Cells were treated with $10 \mu \mathrm{m}$ PCA derivatives for 8 days and then total RNA was extracted and subjected to real-time RT-PCR. Data were first normalized to the level of Gapdh and are presented as fold change versus vehicle controls. Data represent the mean and s.d. of three independent experiments. ${ }^{*} P<0.05,{ }^{* *} P<0.01$ and ${ }^{* * *} P<0.005$, Student's $t$-test, compared with vehicle controls. (d) PPAR $\gamma$ reporter assay. C3H10T1/2 cells and MC3T3-E1 cells were transiently transfected with PPAR-RE-Luc reporter plasmid and PPARy2 and RXR cDNA expression plasmids. After treatment for $24 \mathrm{~h}$ with $10 \mu \mathrm{m} 2 \mathrm{H}-\mathrm{PCA}$, the dual luciferase assay was performed. Data are shown as the mean and s.d. obtained from three independent experiments performed in triplicate. ${ }^{*} P<0.05$, Student's t-test, compared with vehicle controls. A full colour version of this figure is available at the Journal of Antibiotics journal online.

2H-PCA, at the concentration that induced adipogenesis in C3H10T1/2 cells, did not induce significant reporter activation. These results suggest that 2H-PCA does not function as a PPAR $\gamma$ ligand and other important target(s) for the induction of the differentiation should exist.

Taken together, we found a new biological activity of phenazine derivatives in osteoblast and adipocyte differentiation of the two model cell systems. These natural compounds, which have been researched intensively owing to their various biological activities, could help us to investigate the mechanism of osteogenesis and adipogenesis in the two model cell systems through a chemical biology approach.

\section{MATERIALS AND METHODS}

\section{Preparation of the Phenazine derivatives}

$1 \mathrm{H}$-phenazine was obtained from an in-house chemical library.

PCA was purchased from Princeton Bio-molecular Research (Princeton, NJ, USA). 2H-PCA was prepared as reported ${ }^{10}$ and identified by comparison of the spectroscopic data. ${ }^{11}$ For preparation of $2 \mathrm{ME}$ PCA, methyl 2-methoxyphenazine-1-carboxylate was prepared as reported: ${ }^{10}{ }^{1} \mathrm{H}-\mathrm{NMR}\left(400 \mathrm{MHz}, \mathrm{CDCl}_{3}\right)$ d $4.10(3 \mathrm{H}, \mathrm{s}), 4.13(3 \mathrm{H}$, s), $7.74(1 \mathrm{H}, \mathrm{d}, J=10 \mathrm{~Hz}), 7.78(1 \mathrm{H}$, ddd, $J=2,7,8 \mathrm{~Hz}), 7.81(1 \mathrm{H}$, ddd, $J=2,7,8 \mathrm{~Hz}), 8.18(1 \mathrm{H}, \mathrm{dd}, J=2,8 \mathrm{~Hz}), 8.20(1 \mathrm{H}, \mathrm{dd}, J=2$, $8 \mathrm{~Hz}), 8.31(1 \mathrm{H}, \mathrm{d}, J=10 \mathrm{~Hz}) ;{ }^{13} \mathrm{C}-\mathrm{NMR}\left(100 \mathrm{MHz}, \mathrm{CDCl}_{3}\right)$ d 52.8 , $57.0,117.6,119.2,129.5,129.8,129.9,130.9,132.5,138.9,141.6$, 142.3, 144.0, 156.6, 167.2; HR-ESI-MS $m / z 269.0919[\mathrm{M}+\mathrm{H}]^{+}$calcd for $\mathrm{C}_{15} \mathrm{H}_{13} \mathrm{~N}_{2} \mathrm{O}_{3}, 269.0921$. Then, methyl 2-methoxyphenazine-1carboxylate $(29 \mathrm{mg}, 0.11 \mathrm{mmol})$ was dissolved in methanol $(3 \mathrm{ml})$ and $4 \mathrm{~m}$ sodium hydroxide $(6 \mathrm{ml})$. The solution was stirred at room temperature for $2.5 \mathrm{~h}$. The reaction mixture was cooled, acidified with dilute hydrochloric acid and extracted with ethyl acetate. The organic solution was washed with saturated sodium chloride solution, dried over anhydrous sodium sulfate and concentrated under reduced pressure. The resulting residue was purified by semi-preparative high-performance liquid chromatography (35\% acetonitrile water) to give 2ME-PCA $(21 \mathrm{mg}, 76 \%)$ as a yellow solid: ${ }^{1} \mathrm{H}-\mathrm{NMR}$ $\left(400 \mathrm{MHz}, \mathrm{CDCl}_{3}\right)$ d $4.29(3 \mathrm{H}, \mathrm{s}), 7.89(1 \mathrm{H}, \mathrm{ddd}, J=1,7,9 \mathrm{~Hz})$, $7.92(1 \mathrm{H}, \mathrm{d}, J=10 \mathrm{~Hz}), 7.97(1 \mathrm{H}, \mathrm{ddd}, J=1,7,9 \mathrm{~Hz}), 8.21(1 \mathrm{H}, \mathrm{dd}$, $J=1,9 \mathrm{~Hz}), 8.26(1 \mathrm{H}, \mathrm{dd}, J=1,9 \mathrm{~Hz}), 8.46(1 \mathrm{H}, \mathrm{d}, J=10 \mathrm{~Hz}) ;{ }^{13} \mathrm{C}-$ NMR $\left(100 \mathrm{MHz}, \mathrm{CDCl}_{3}\right)$ d 57.7, 107.9, 120.9, 127.3, 129.8, 130.4, 133.1, 135.8, 139.4 (2C), 141.8, 142.0, 164.5, 165.6; HR-ESI-MS m/z 255.0763 $[\mathrm{M}+\mathrm{H}]^{+}$calcd for $\mathrm{C}_{14} \mathrm{H}_{11} \mathrm{~N}_{2} \mathrm{O}_{3}, 255.0764$.

\section{Cell culture}

Mouse C3H10T1/2 cells were cultured in Dulbecco's modified Eagle's medium (Wako Pure Chemical, Osaka, Japan) containing 10\% fetal bovine serum and 1\% penicillin/streptomycin. Mouse MC3T3-E1 cells were cultured in MEM $\alpha$ (Wako Pure Chemical) containing 10\% fetal bovine serum and $1 \%$ penicillin/streptomycin. To induce cellular differentiation, cells were plated in 96-well plates at a density of 10000 cells per well or in 6-well plates at a density of 400000 cells per well. After reaching confluence, cells were treated with compounds.

\section{PPAR $\gamma$ reporter assay}

C3H10T1/2 cells and MC3T3-E1 cells were transiently transfected with PPAR-RE-Luc reporter plasmid and PPAR $\gamma 2$ and RXR cDNA expression plasmids using FuGeneHD transfection reagent (Promega, Madison, WI, USA) according to the manufacturer's instructions. One 
day after transfection, the cells were treated with $10 \mu \mathrm{M}$ troglitazone or $10 \mu \mathrm{M} 2 \mathrm{H}-\mathrm{PCA}$ in OPTI-MEM medium (Invitrogen, Carlsbad, CA, USA) containing $5 \%$ fetal bovine serum. After $24 \mathrm{~h}$, cells were assayed for firefly and Renilla luciferase activities using the Dual-Glo Luciferase Assay System (Promega) according to the manufacturer's instructions.

Other experiments such as ALP staining, ALP assay, Oil Red O staining and real-time reverse-transcription PCR were performed as previously described. ${ }^{6,7}$

\section{DEDICATION}

This paper is dedicated to Professor Satoshi Ōmura on the occasion of his Nobel Prize in Physiology or Medicine 2015.

\section{CONFLICT OF INTEREST}

The authors declare no conflict of interest.

\section{ACKNOWLEDGEMENTS}

We thank I Momose, M Igarashi, S Ohba and M Arakawa for their helpful comments and technical support. This work was supported in part by a grantin-aid from the Ministry of Education, Culture, Sports, Science and Technology of Japan (to SS, number 20790218 and 24102532).
1 Nombela-Arrieta, C., Ritz, J. \& Silberstein, L. E. The elusive nature and function of mesenchymal stem cells. Nat. Rev. Mol. Cell Biol. 12, 126-131 (2011).

2 Komori, T. Regulation of osteoblast differentiation by transcription factors. J. Cell. Biochem. 99, 1233-1239 (2006).

3 Cristancho, A. G. \& Lazar, M. A. Forming functional fat: a growing understanding of adipocyte differentiation. Nat. Rev. Mol. Cell Biol. 12 722-734 (2011).

4 Pierson, L. S. III \& Pierson, E. A. Metabolism and function of phenazines in bacteria: impacts on the behavior of bacteria in the environment and biotechnological processes. Appl. Microbiol. Biotechnol. 86, 1659-1670 (2010).

5 Wu, X., Walker, J., Zhang, J., Ding, S. \& Schultz, P. G. Purmorphamine induces osteogenesis by activation of the Hedgehog signaling pathway. Chem. Biol. 11, 1229-1238 (2004).

6 Sakamoto, S. et al. Decalpenic acid, a novel small molecule from Penicillium verruculosum CR37010, induces early osteoblastic markers in pluripotent mesenchymal cells. J. Antibiot. 63, 703-708 (2010).

7 Sakamoto, S. et al. Decalpenic acid induces early osteoblastic markers in pluripotent mesenchymal cells via activation of retinoic acid receptor $\gamma$. Biochem. Biophys. Res. Commun. 422, 751-757 (2012).

8 Huang, H. et al. BMP signaling pathway is required for commitment of C3H10T1/2 pluripotent stem cells to the adipocyte lineage. Proc. Natl Acad. Sci. USA 106 12670-12675 (2009).

9 Bäckesjö, C. M., Li, Y., Lindgren, U. \& Haldosén, L. A. Activation of Sirt1 decreases adipocyte formation during osteoblast differentiation of mesenchymal stem cells. J. Bone Miner. Res. 21, 993-1002 (2006).

10 Brooke, P. K. et al. Synthesis of some methoxy- and hydroxy-phenazine-1carboxylic acids. JCS Perkin1 16, 2248-2251 (1976).

11 Mehnaz, S. et al. Lahorenoic acids A-C, ortho-dialkyl-substituted aromatic acids from the biocontrol strain Pseudomonas aurantiaca PB-St2. J. Nat. Prod. 76, 135-141 (2013).

Supplementary Information accompanies the paper on The Journal of Antibiotics website (http://www.nature.com/ja) 